\title{
Impact of surgeon rhBMP-2 cost awareness on complication rates and health system costs for spinal arthrodesis
}

\author{
Margaret McGrath, MD, ${ }^{1}$ Abdullah H. Feroze, MD, ${ }^{1}$ Dominic Nistal, MD, ${ }^{1}$ Emily Robinson, $B S,{ }^{2}$ and \\ Rajiv Saigal, MD, PhD'1
}

${ }^{1}$ Department of Neurological Surgery and ${ }^{2}$ School of Medicine, University of Washington, Seattle, Washington

OBJECTIVE Recombinant human bone morphogenetic protein-2 (rhBMP-2) is used in spinal arthrodesis procedures to enhance bony fusion. Research has suggested that it is the most cost-effective fusion enhancer, but there are significant upfront costs for the healthcare system. The primary objective of this study was to determine whether intraoperative dosing and corresponding costs changed with surgeon cost awareness. The secondary objective was to describe surgical complications before and after surgeon awareness of rhBMP-2 cost.

METHODS A retrospective medical record review was conducted to identify patients who underwent spinal arthrodesis procedures performed by a single surgeon, supplemented with rhBMP-2, from June 2016 to June 2018 . Collected data included rhBMP-2 dosage, rhBMP-2 list price, and surgical complications. Expected Medicare reimbursement was calculated. Data were analyzed before and after surgeon awareness of rhBMP-2 cost.

RESULTS Forty-eight procedures were performed using rhBMP-2, 16 before and 32 after surgeon cost awareness. Prior to cost awareness, the most frequent rhBMP-2 dosage level was $x$-small $(38.9 \%, n=7)$, followed by large $(27.8 \%$, $n=5)$ and small $(22.2 \%, n=4)$. After cost awareness, the most frequent rhBMP-2 dosage was $x x-s m a l l ~(56.8 \%, n=21)$, followed by $x$-small $(21.6 \%, n=8)$ and large $(13.5 \%, n=5)$. The rhBMP-2 average cost per surgery was $\$ 4116.56$ prior to surgeon cost awareness versus $\$ 2268.38$ after. Two complications were observed in the pre-cost awareness surgical group; 2 complications were observed in the post-cost awareness surgical group.

CONCLUSIONS Surgeon awareness of rhBMP-2 cost resulted in use of smaller rhBMP-2 doses, decreased rhBMP-2 cost per surgery, and decreased overall hospital admission charges, without a detectable increase in surgical complications.

https://thejns.org/doi/abs/10.3171/2021.3.FOCUS2152

KEYWORDS cost awareness; spinal arthrodesis; surgery costs; surgeon behavior; bone morphogenetic protein; spine surgery

$\mathrm{S}$ PINAL arthrodesis is commonly performed to treat a variety of spinal pathologies. There are multiple strategies to enhance bony fusion, including use of bone autograft, allograft, bone substitutes, and biologics to stimulate bone growth and enhance the rate of fusion. ${ }^{1,2}$ The two methods can be used either independently or simultaneously to enhance fusion outcomes. Iliac crest autograft is the current gold standard for bone autograft but is associated with donor-site morbidity. ${ }^{1}$ Recombinant human bone morphogenetic protein-2 (rhBMP-2), a natu- rally occurring protein that stimulates bone growth, ${ }^{1-5}$ was proposed to replace iliac bone crest autograft in enhancing bony fusion. Since its introduction to the commercial market in 2002, rhBMP-2 has been increasingly used in spinal arthrodesis procedures. ${ }^{1,6,7}$ Both short-term and long-term results have shown efficacy in enhancing arthrodesis rates after anterior lumbar interbody fusion (ALIF). ${ }^{8,9}$ Despite the 2008 FDA advisory regarding its use $\mathrm{e}^{10}$ and reports describing potential adverse side effects, rhBMP-2 is still frequently used in spinal arthrodesis cases because of its

ABBREVIATIONS ALIF = anterior lumbar interbody fusion; OR = operating room; rhBMP-2 = recombinant human bone morphogenetic protein-2; USD = US dollars; UW = University of Washington. 
efficacy in osteoinduction. ${ }^{11-14}$ Although it is currently only FDA approved for ALIF, rhBMP-2 is frequently used in an off-label fashion. ${ }^{11,15}$

Control of healthcare costs is a primary concern for present healthcare policy. The upfront cost of rhBMP-2 for the hospital can range from approximately $\$ 900$ to more than $\$ 5500$, depending on the dose provided, which is based on a patient's age, sex, surgical procedure, and bone quality, among other factors. Given the increasing use of rhBMP-2, reducing the economic burden is of high yield to healthcare facilities. The cost-effectiveness of rhBMP-2 compared with other fusion enhancers has been studied. ${ }^{16,17}$ However, there is a paucity of data on rhBMP-2 cost utilization, or on the effect of surgeon awareness of rhBMP-2 cost on utilization and patient outcome. The primary goal of this research was to determine whether intraoperative rhBMP-2 dosing management was altered by surgeon cost awareness. The secondary objective was to describe surgical complications associated with rhBMP-2 doses before and after surgeon cost awareness.

\section{Methods}

A retrospective medical record review was performed to identify patients $>18$ years of age who underwent spinal fusion surgeries performed by a single surgeon at a single institution from June 2016 to June 2018 and in which rhBMP-2 was used. A single surgeon was selected to control for surgical methods, implant types, and types of cases in which rhBMP-2 was used. This study was reviewed by our IRB and determined to be a quality assurance and quality improvement activity that did not require IRB review, consistent with federal and state regulations.

Patients were identified using Medicare Severity Diagnosis Related Group codes that included spinal fusion procedures. They were then filtered to include only those fusion procedures that were supplemented with rhBMP-2. Medical records were retrospectively reviewed to identify complications possibly associated with rhBMP-2 usage, including heterotopic ossification, osteolysis, seroma/ hematoma, wound infection, wound dehiscence, arachnoiditis, dysphagia (specifically with cervical surgery), increased neurological deficits (myelopathy, radiculopathy), and retrograde ejaculation. Patients lost to follow-up were excluded from the analysis of complications. A chi-square test analysis of complication rates was performed.

RhBMP-2 (Infuse bone graft, Medtronic) was used in all patients. ${ }^{18}$ The product dose ranged from xx-small kits $(1.05 \mathrm{mg})$ to large kits $(12 \mathrm{mg})$; University of Washington (UW) dose ranges, list prices, and charges to payer are shown in Table 1. The list price and charge-to-payer data were supplied by the UW Medicine Financial Department and approved by Medtronic for publication. The 12-mg kits are not purchased by UW; therefore, information for this dosage level was not available. The dosage chosen for each surgery was made on a case-by-case basis, based on surgeon preference and experience. If more than 1 kit was used for a surgical procedure, this was recorded. As part of institutional efforts to reduce implant costs, surgeons at the institution were made aware of the full range of rhBMP-2 doses and costs. The full price list was provided
TABLE 1. RhBMP-2 dose pricing

\begin{tabular}{cccc}
\hline $\begin{array}{c}\text { Infuse Kit rhBMP-2 } \\
\text { Dosage Size }\end{array}$ & $\begin{array}{c}\text { Dose } \\
(\mathrm{mg})\end{array}$ & $\begin{array}{c}\text { List } \\
\text { Price }^{*}\end{array}$ & $\begin{array}{c}\text { Charge to } \\
\text { Payer† }\end{array}$ \\
\hline XX-small & 1.05 & $\$ 898.00$ & $\$ 7,004.40$ \\
\hline X-small & 2.1 & $\$ 1,850.00$ & $\$ 10,915.00$ \\
\hline Small & 4.2 & $\$ 3,695.00$ & $\$ 21,800.00$ \\
\hline Medium & 8.4 & $\$ 5,145.00$ & $\$ 23,667.00$ \\
\hline Large & 12 & $\$ 5,569.00$ & $\$ 25,617.00$ \\
\hline
\end{tabular}

* List price is the cost to obtain the product for the institution.

† Charge to the payer is the amount charged to the payer for the product.

electronically. After becoming aware of rhBMP-2 costs, the surgeon continued to operate with no changes to patient demographics or caseload.

Cost data for each surgery were extracted by the UW Medicine Financial Department. Expected Medicare reimbursement was calculated for each surgery regardless of actual payer. Expected Medicare reimbursement was derived by employing a Medicare inpatient reimbursement model developed by the UW Medicine Government Payers team for purposes of calculating anticipated Medicare Severity Diagnosis Related Group-based payments. This Excel-based model was applied to the data from each patient to calculate the expected US dollars (USD) amount that Medicare would have reimbursed our institution if Medicare were paying. Descriptive statistics were calculated using Microsoft Office Excel. Differences between groups were assessed using the Mann-Whitney U-test, and significance was assessed at $\mathrm{p}<0.05$.

\section{Results}

From June 2016 to June 2018, a total of 48 patients were identified who underwent surgery supplemented with rhBMP-2 and for whom follow-up data were available (Table 2). A total of 177 levels were fused (19.8\% cervical, $36.2 \%$ thoracic, and $44.1 \%$ lumbar). Sixteen surgeries were performed prior to surgeon cost awareness, and 32 were performed after cost awareness. The surgeries were performed for a variety of pathologies; degenerative disease, trauma, and deformity were the leading pathologies. Fifty percent of patients in the pre-cost awareness group had degenerative disease versus $37.5 \%$ in the postcost awareness group. Trauma was the reason for $18.8 \%$ of pre-cost awareness patients versus $37.5 \%$ of post-cost awareness patients, while deformity was the pathology for $31.2 \%$ of pre-cost awareness patients and $9.4 \%$ of postcost awareness patients (see Table 3). The majority of the procedures were open procedures (13/16 in the pre-cost awareness group, 30/32 in the post-cost awareness group). The mean $( \pm \mathrm{SD})$ number of fused levels for the pre-cost awareness group was $3.94 \pm 4.07$, and for the post-cost awareness group it was $2.97 \pm 2.80$. No significant difference between the mean number of fused levels was detected when analysis was carried out using the two-sided Mann-Whitney U-test $(p=0.493)$. For the 16 surgeries performed before surgeon cost awareness, 18 rhBMP-2 dosage kits were used. After surgeon cost awareness, 37 
TABLE 2. Demographics of patients undergoing surgery supplemented with rhBMP-2 in pre-and post-cost awareness groups

\begin{tabular}{|c|c|c|c|}
\hline Variable & Pre-Cost Awareness Group $(n=16)$ & Post-Cost Awareness Group $(n=32)$ & Total $(n=48)$ \\
\hline Age (yrs) & $63.5 \pm 10.4$ & $57.3 \pm 15.6$ & $59.4 \pm 14.4$ \\
\hline Race & $\begin{array}{l}\text { 75.0\% White }(n=12) ; 6.2 \% \text { Black }(n= \\
1) ; 12 \% \text { Hispanic }(n=2) ; 6.2 \% \text { Asian } \\
(n=1)\end{array}$ & $\begin{array}{l}90.6 \% \text { White }(n=29) ; 3.1 \% \text { Black }(n \\
\quad=1) ; 0.0 \% \text { Hispanic }(n=0) ; 6.2 \% \\
\text { Asian }(n=2)\end{array}$ & $\begin{array}{l}\text { 85.4\% White }(n=41) ; 4.2 \% \text { Black }(n \\
\quad=2) ; 4.2 \% \text { Hispanic }(n=2) ; 6.2 \% \\
\text { Asian }(n=3)\end{array}$ \\
\hline Smoking status & $\begin{array}{l}62.5 \% \text { nonsmoker }(n=10) ; 12.5 \% \\
\text { active smoker }(n=2) ; 25 \% \text { remote } \\
\text { smoker }(n=4)\end{array}$ & $\begin{array}{l}37.5 \% \text { nonsmoker }(n=12) ; 21.9 \% \\
\text { active smoker }(n=7) ; 40.6 \% \text { remote } \\
\text { smoker }(n=13)\end{array}$ & $\begin{array}{l}45.8 \% \text { nonsmoker }(n=22) ; 18.75 \% \\
\text { active smoker }(n=9) ; 35.4 \% \text { remote } \\
\text { smoker }(n=17)\end{array}$ \\
\hline $\begin{array}{l}\text { Elective vs nonelective } \\
\text { surgery }\end{array}$ & $\begin{array}{l}56.3 \% \text { elective }(n=9) ; 43.7 \% \text { nonelec- } \\
\quad \text { tive }(n=7)\end{array}$ & $\begin{array}{l}31.2 \% \text { elective }(n=10) ; 68.8 \% \text { non- } \\
\quad \text { elective }(n=22)\end{array}$ & $\begin{array}{l}39.6 \% \text { elective }(n=19) ; 60.4 \% \text { non- } \\
\quad \text { elective }(n=29)\end{array}$ \\
\hline LOS (days) & $13 \pm 15$ & $8 \pm 6$ & $10 \pm 10$ \\
\hline Levels fused & $\begin{array}{c}4 \pm 4 \\
\text { 14.5\% cervical }(n=11) ; 36.8 \% \text { thoracic } \\
(n=28) ; 48.7 \% \text { lumbar }(n=37)\end{array}$ & $\begin{array}{l}3 \pm 3 \\
23.8 \% \text { cervical }(n=24) ; 35.6 \% \text { tho- } \\
\text { racic }(n=36) ; 40.6 \% \text { lumbar }(n=41)\end{array}$ & $\begin{array}{c}4 \pm 3 \\
\begin{array}{c}19.8 \% \text { cervical }(n=35) ; 36.2 \% \text { thoracic } \\
(n=64) ; 44.1 \% \text { lumbar }(n=78)\end{array}\end{array}$ \\
\hline
\end{tabular}

LOS = length of stay.

Mean values are presented as the mean \pm SD.

dosage kits were used for the 32 surgeries performed. Awareness of rhBMP- 2 cost resulted in increased usage of smaller dosages. Changes in rhBMP-2 xx-small doses administered before and after surgeon cost awareness are shown in Fig. 1. Prior to cost awareness, the most frequent rhBMP-2 dosage level chosen was $\mathrm{x}$-small $(38.9 \%, \mathrm{n}=7)$, followed by large $(27.8 \%, n=5)$, small $(22.2 \%, n=4)$, and medium $(11.1 \%, \mathrm{n}=2)$; $\mathrm{xx}$-small was not chosen. After cost awareness, the most frequent rhBMP-2 dosage level chosen was xx-small $(56.8 \%, \mathrm{n}=21)$, followed by $\mathrm{x}$-small $(21.6 \%, n=8)$, large $(13.5 \%, n=5)$, and small $(8.1 \%, n=3)$; medium was not chosen. Of note, the operating surgeon used demineralized bone matrix and allograft cancellous bone chips as needed for bone substitutes and extenders, both before and after rhBMP-2 cost awareness. There was no change in the use of bone extenders before and after rhBMP-2 cost awareness. Pre- and post-cost awareness dosage changes also resulted in changes in the average cost for rhBMP-2 per surgery. Prior to cost awareness, dosage choices resulted in a mean rhBMP-2 cost per surgery of $\$ 4116.56 \pm \$ 2295.59$. After cost awareness, dosage choices resulted in a mean cost per surgery of $\$ 2268.38 \pm$ $\$ 3049.24$, a statistically significant $44.9 \%$ reduction in the amount spent on rhBMP-2 per surgery $(\mathrm{p}<0.001$; Table 4 and Fig. 2). When expected Medicare reimbursement was calculated, prior to surgeon cost awareness, rhBMP-2 costs encompassed $7.6 \% \pm 4.1 \%$ of the expected Medicare reimbursement for hospital charges for the overall admission. After cost awareness, rhBMP-2 costs encompassed $3.3 \% \pm 2.4 \%$ of the expected Medicare reimbursement for hospital charges for the overall admission, a statistically significant $56.2 \%$ reduction in Medicare reimbursement allocated to rhBMP-2 ( $<<0.001$; Table 4 and Fig. 3).

The mean patient follow-up was $107 \pm 64.6$ weeks (range 12-205 weeks). Surgical complications are shown in Table 5. Of the 48 patients in the study, 40 were included in long-term follow-up, and 8 patients were lost to follow-up due to the following reasons: death $(n=3)$, insurance $(\mathrm{n}=1)$, and unknown $(\mathrm{n}=4)$. Of the 16 patients undergoing surgery before surgeon cost awareness, all had available cost data; 1 was lost to follow-up and 2 (12.5\%) of the remaining 15 patients experienced complications. One of these patients experienced a postoperative epidural seroma with bilateral lower-extremity weakness requiring seroma evacuation. The other patient experienced pseudarthrosis with a rod breakage, requiring revision surgery. Of the 32 patients in the post-cost awareness group, all had available cost data; 7 were lost to long-term follow-up, and $2(6.2 \%)$ of the remaining 25 patients experienced a complication. One patient developed pseudarthrosis with a rod breakage requiring revision surgery, and another patient had screw loosening that was preceded by a groundlevel fall. Thus, the pseudarthrosis rate was $6.7 \%$ in the pre-cost awareness group and $4 \%$ in the post-cost awareness group.

\section{Discussion}

Back pain is a substantial cost to the US healthcare system,,$^{19}$ and the volume of spinal arthrodesis cases has been increasing, accompanied by increasing hospital costs. ${ }^{20,21}$

TABLE 3. Characteristics of cases pre- and post-cost awareness

\begin{tabular}{lcc}
\hline \multirow{2}{*}{ Case Type } & \multicolumn{2}{c}{ No. of Patients (\%) } \\
\cline { 2 - 3 } & $\begin{array}{c}\text { Pre-Cost } \\
\text { Awareness }(\mathrm{n}=16)\end{array}$ & $\begin{array}{c}\text { Post-Cost } \\
\text { Awareness }(\mathrm{n}=32)\end{array}$ \\
\hline Degenerative & $8(50)$ & $12(37.5)$ \\
\hline Deformity & $5(31.2)$ & $3(9.4)$ \\
\hline Trauma & $3(18.8)$ & $12(37.5)$ \\
\hline Idiopathic spondylolisthesis & $0(0)$ & $1(3.1)$ \\
\hline Tumor & $0(0)$ & $1(3.1)$ \\
\hline Infection & $0(0)$ & $2(6.2)$ \\
\hline Other* & $0(0)$ & $1(3.1)$ \\
\hline Interbody cage & $7(43.8)$ & $15(46.9)$ \\
\hline
\end{tabular}

* "Other" category includes pathologic fracture of unknown etiology. 


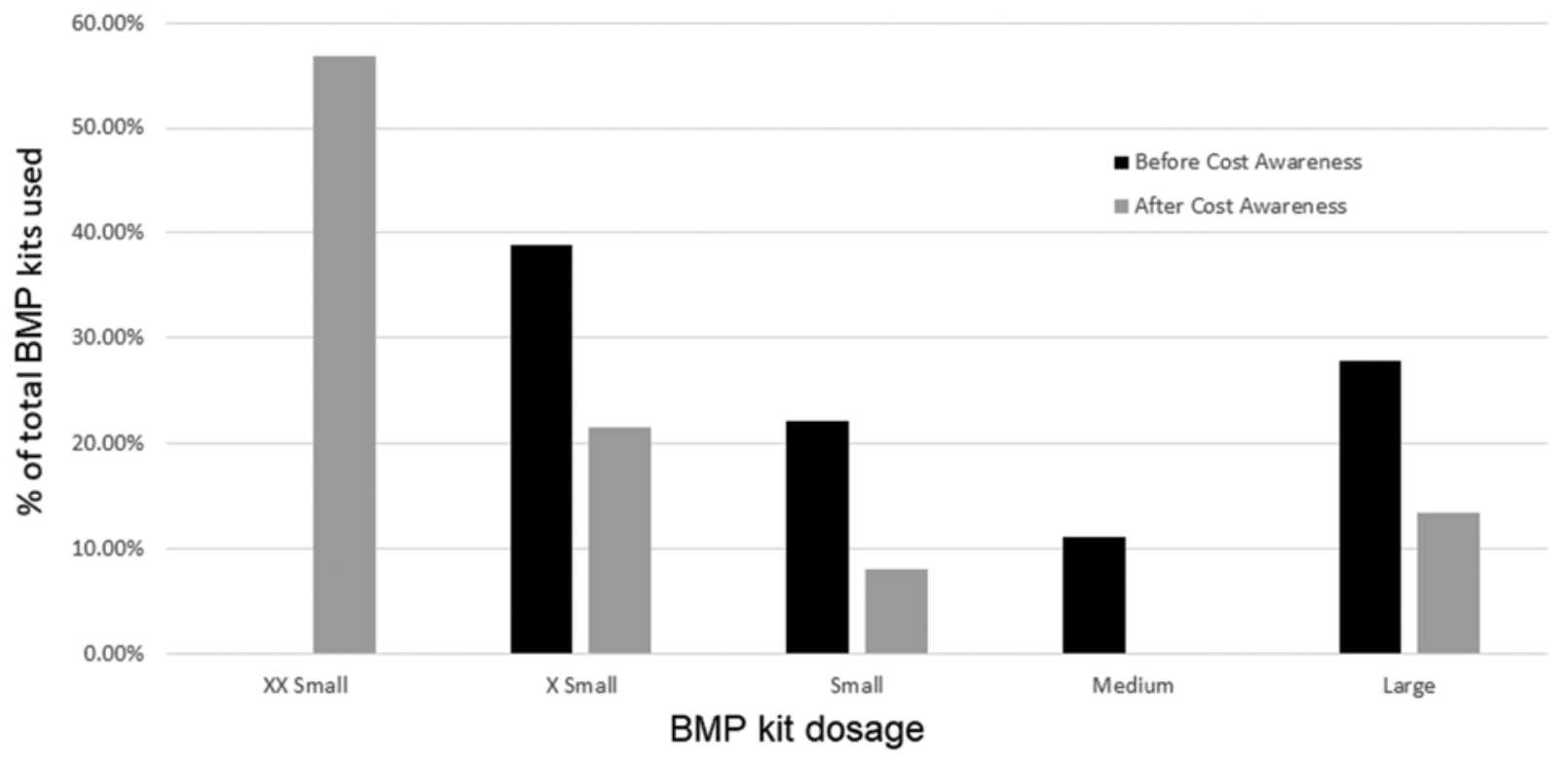

FIG. 1. Percentage of total rhBMP-2 kits used, by size of kit, before and after surgeon cost awareness.

In 2015, an estimated $\$ 24.3$ billion was spent on inpatient fusion procedures. ${ }^{20}$ RhBMP-2 is frequently used to enhance fusion in these procedures. While rhBMP-2 is only FDA approved for ALIF, it is used for fusion enhancement in a variety of procedures at the discretion of the surgeon. Its use is commonly affected by pathology, patient age, and bone quality, among other factors. The decision for when to use rhBMP-2 is surgeon dependent and highly variable. In addition, there is tremendous disparity in rhBMP-2 doses used for specific spinal fusion procedures, with no clear guidelines as to the minimum effective dose..$^{22}$ Furthermore, the high upfront costs for rhBMP-2 result in substantial charges to the healthcare payer, at a time when control of costs is a primary healthcare policy concern. This pilot study demonstrated that awareness of the costs associated with using rhBMP-2 led to the use of smaller doses, thereby reducing overall cost of hospital admissions associated with these surgeries, as well as the overall percentage of inpatient revenue costs as represented by Medicare reimbursement, but without increasing complication rates such as for pseudarthrosis. Larger studies are needed to further validate these findings.

These findings are similar to those of previous studies showing that, although surgeons have poor knowledge of operating room (OR) costs, providing information about surgical costs is one possible approach to reducing OR supply costs. ${ }^{23-25}$ Multiple studies have shown that surgeons are generally unaware of intraoperative costs, and cost awareness is an effective method to reduce intraoperative dosing. ${ }^{26-28}$ Methods for making surgeons aware of intraoperative costs that have been previously studied include individual score cards ${ }^{26}$ for surgeons to retrospectively view their individual spending reports and displaying surgical item receipts in the OR. ${ }^{23}$ Additionally, surgeons can reach out to hospital financial departments with specific inquiries, as did the surgeon in our study. The majority of the revenue for surgery-related admissions is generated by OR charges..$^{29}$ By decreasing intraoperative costs, overall admission costs may also decrease. Other research has described various approaches to increasing surgeon awareness of intraoperative costs, including cost awareness and feedback, financial incentives, standardization of operations to increase uniformity of high-cost items, and switching to reusable materials from disposable. ${ }^{27}$

Together with increased awareness of surgical costs, robust cost-effectiveness data are important to inform surgical decision-making. The cost-effectiveness of rhBMP-2

TABLE 4. Effect on the mean rhBMP-2 cost and expected Medicare reimbursement per surgery before and after surgeon cost awareness

\begin{tabular}{lcccc}
\hline $\begin{array}{c}\text { Surgeon Cost } \\
\text { Awareness }\end{array}$ & $\begin{array}{c}\text { No. of } \\
\text { Surgeries }\end{array}$ & $\begin{array}{c}\text { Mean BMP } \\
\text { Cost }^{*}\end{array}$ & $\begin{array}{c}\text { Expected Medicare } \\
\text { Reimbursement }\end{array}$ & $\begin{array}{c}\text { Mean BMP Cost as \% of Expected Medicare } \\
\text { Reimbursement }\end{array}$ \\
\hline Before & 16 & $\$ 4,116.56 \pm 2,295.59$ & $\$ 60,441.77 \pm 26,624.13$ & $7.6 \pm 4.1 \%$ \\
\hline After & 32 & $\$ 2,268.38 \pm 3,049.24$ & $\$ 61,981.00 \pm 30,023.01$ & $3.3 \pm 2.4 \%$ \\
\hline Difference & & $\$-1,848.19$ & $\$ 1,539.23$ & $-4.3 \%$ \\
\hline Total & 48 & $\$ 2,884.44$ & $\$ 61,467.93$ & $4.8 \%$ \\
\hline$p$ value & & $<0.001$ & 0.673 & $<0.001$ \\
\hline
\end{tabular}

* per surgery. 


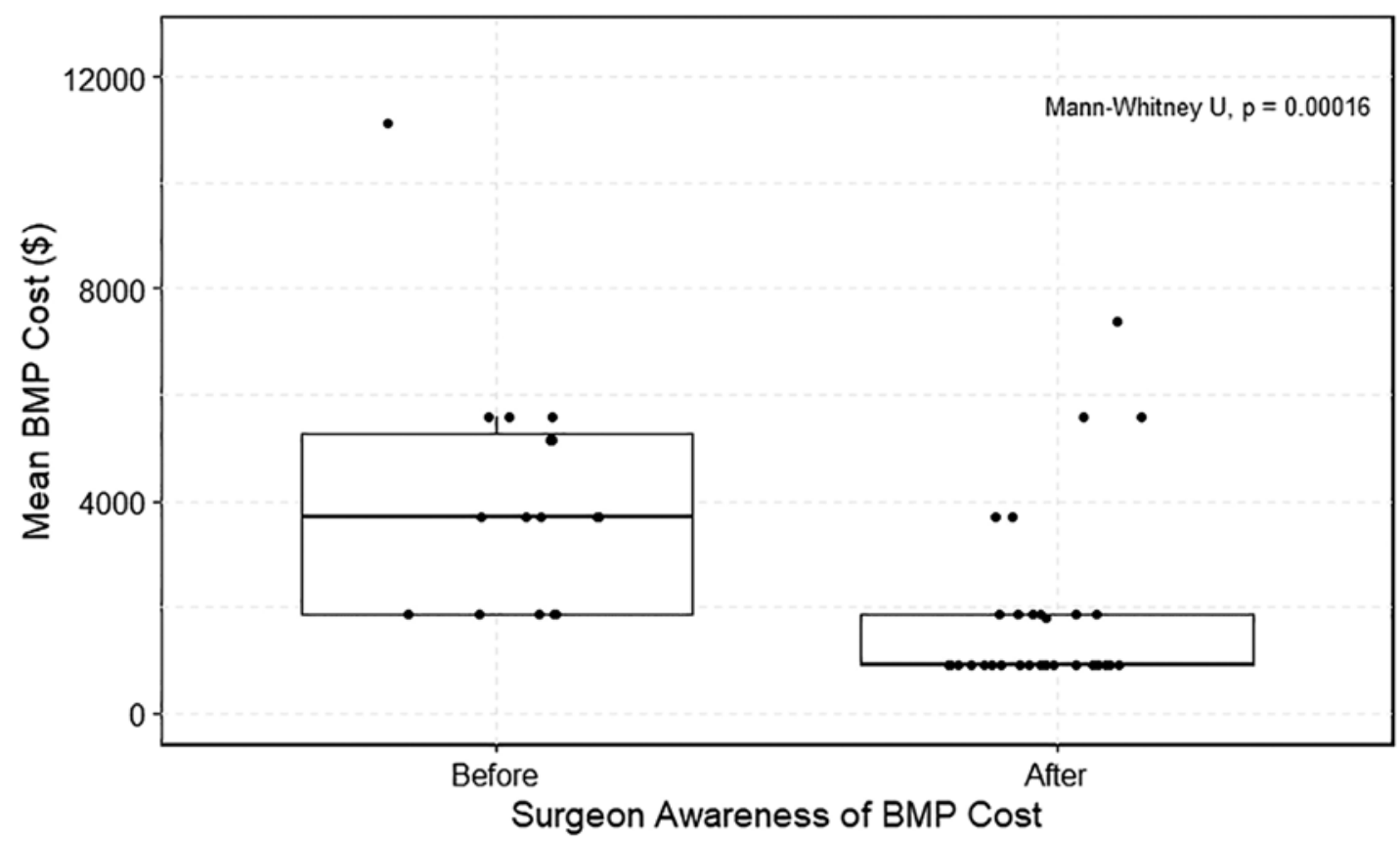

FIG. 2. Mean cost of rhBMP-2 in USD for surgeries performed before and after surgeon cost awareness.

has been compared with iliac crest bone graft, local bone alone, demineralized bone matrix with local bone, and local bone with corticocancellous allograft chips; overall, rhBMP-2 has been suggested to be the most cost-effective fusion enhancer. ${ }^{30}$ However, rhBMP-2 cost-effectiveness studies have yielded mixed results and recommendations. Some authors have reported that the increased upfront costs and complications associated with rhBMP-2 are offset by a reduced rate of revision surgery ${ }^{16}$ Others have suggested that, despite the reduced revision rate, increasing use of rhBMP-2 does not always correlate with a decreasing use of allograft, leading to a substantial increase in costs with no cost benefit. ${ }^{7}$ Some argue that rhBMP-2 is most effective when used alone, rather than in conjunction with iliac crest autograft. ${ }^{17}$ Of note, no patients in this study received iliac crest autograft. One potential risk of rhBMP-2 cost awareness is a reduced use of rhBMP-2 while increasing utilization of other costly implants, such

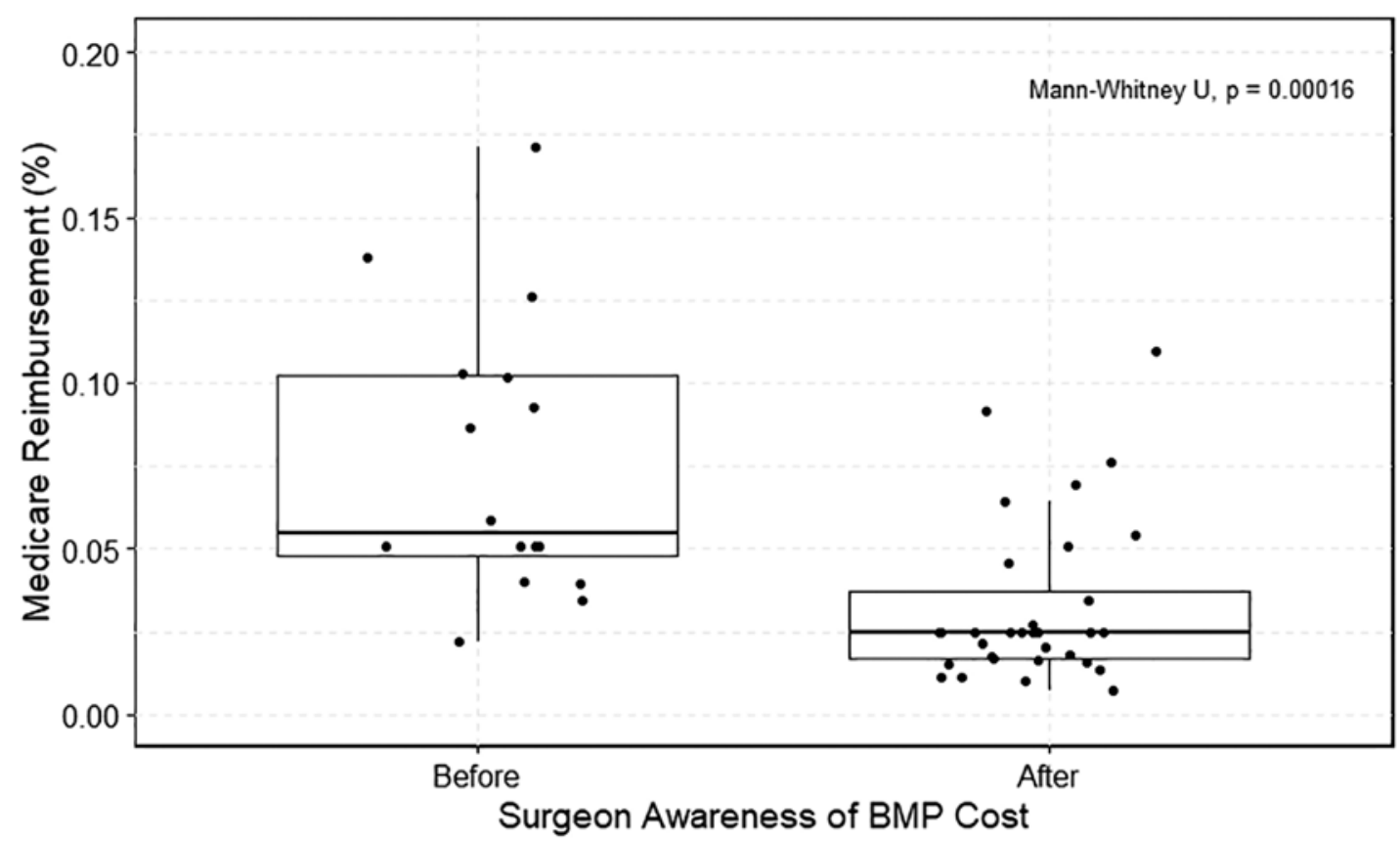

FIG. 3. Expected Medicare reimbursement for rhBMP-2 for surgeries performed before and after surgeon cost awareness. 
TABLE 5. Surgical complications before and after surgeon awareness of rhBMP-2 dosage cost

\begin{tabular}{cccc}
\hline \multirow{2}{*}{$\begin{array}{c}\text { Surgeon Cost } \\
\text { Awareness }\end{array}$} & \multicolumn{3}{c}{ No. of Surgeries (\%) } \\
\cline { 2 - 4 } & Total & Lost to Follow-Up & Complication \\
\hline Before & 16 & $1(6.2)$ & $2(12.5)^{\star}$ \\
\hline After & 32 & $7(21.9)$ & $2(6.2) \dagger$ \\
\hline Total & 48 & $8(16.7)$ & $4(8.3)$ \\
\hline
\end{tabular}

* 1 seroma formation resulting in evacuation and bilateral lower-extremity weakness, and 1 pseudarthrosis with rod breakage resulting in revision surgery.

$\dagger 1$ pseudarthrosis with rod breakage resulting in revision surgery

as interbody cages, and bone extenders. In this study, interbody cages and bone extenders had the same usage preand post-cost awareness. Similarly, future studies should control for all implant costs when measuring cost changes.

RhBMP-2 has been associated with several complications, including heterotopic ossification, osteolysis, seroma/hematoma, infection, arachnoiditis, dysphagia (anterior cervical surgery), increased neurological deficits (myelopathy, radiculopathy), retrograde ejaculation, and cancer. ${ }^{7,14,31-41}$ In this study, we observed a minimal number of possible rhBMP-2-associated complications for surgeries performed both before and after surgeon awareness of rhBMP-2 cost, consistent with previously reported studies. We detected no difference in complication rates before or after surgeon cost awareness.

Important limitations of the study include its small sample size and single-surgeon nature. The sample size was limited by the surgeon's operative volume prior to their awareness of the cost of rhBMP-2, resulting in a larger post-cost awareness sample size. This study presents data from procedures performed by a single surgeon only. We decided to focus this pilot study on a single surgeon to control for surgical methods, implant types, and types of cases in which rhBMP-2 was used. Additionally, we excluded other surgeons at the institution from this pilot study because a specific date was not available regarding when they were previously made aware of rhBMP-2 costs, precluding a clean pre- and post-cost awareness analysis. Thus, these findings could have limited generalizability. However, our findings are consistent with those of other published reports related to surgeon cost awareness, as cited above. We hypothesize that a larger sample size with multiple institutions and surgeons would lead to similar cost findings. These studies are now warranted based on our findings.

Long-term follow-up was limited for some of our trauma patients, many of whom lived distant from the medical center. The study center is a level 1 trauma center that serves a geographically diverse population with a high percentage of patients living within a 5-state radius, resulting in higher rates of loss to long-term follow-up, in spite of repeated attempts to contact distant patients. In these patients, it is possible that they had complications treated at outside facilities and did not report back to us. However, our electronic health record system does integrate and make available many outside records, and yet we found no additional reported complications beyond the ones we recorded. We deliberately limited the study only to cases in which rhBMP-2 was used. Before and after surgeon cost awareness, there was no change in the types of cases in which rhBMP-2 was used. These continued to be cases with a higher risk of nonunion, including those with patients who were smokers, elderly, had low bone density, and cases in which there was limited fusion surface (e.g., minimally invasive surgery interbody fusion cases).

This study has some limitations in addition to the small sample size and retrospective design. Private payer data are proprietary, and thus could not be included in the study. As such, we were not permitted access to institutional data related to operational and contribution margins, which could contribute to additional insights. Medicare reimbursement is publicly available information, and for this reason, it was used as a standardized representation for reimbursement.

Future studies should compare cost awareness in large sample groups and among a variety of surgeons. This study provided preliminary data regarding complication comparison for higher versus lower rhBMP-2 doses; future studies should assess complication rates, including rates of pseudarthrosis and fusion outcomes in higher versus lower rhBMP-2 doses.

\section{Conclusions}

This study provided the first reported data on rhBMP-2 dosage utilization in spinal arthrodesis procedures before and after surgeon cost awareness. Surgeon awareness of rhBMP-2 cost resulted in a preference for smaller, less expensive doses of rhBMP-2, with a corresponding overall decrease in rhBMP-2 cost in this cohort, thereby reducing overall hospital admission charges. Use of rhBMP-2 is widespread and seen as a useful fusion adjunct for spine surgeons, but many are not aware of the availability of the xx-small 1.05-mg dose or the cost differential between different dosing options. This study suggested that surgeon awareness of rhBMP-2 cost may provide a potential approach to reducing healthcare costs associated with spinal arthrodesis procedures and emphasized the need for additional data on dose-related efficacy and morbidity associated with rhBMP-2 usage in these procedures.

\section{Acknowledgments}

We thank Sharon Durfy, PhD, for her assistance with manuscript preparation; Jason Barber, MS, for assistance with statistical analysis; and the University of Washington Financial Department for assistance with data collection.

\section{References}

1. Burke JF, Dhall SS. Bone morphogenic protein use in spinal surgery. Neurosurg Clin N Am. 2017;28(3):331-334.

2. Goulet JA, Senunas LE, DeSilva GL, Greenfield ML. Autogenous iliac crest bone graft. Complications and functional assessment. Clin Orthop Relat Res. 1997;(339):76-81.

3. Banwart JC, Asher MA, Hassanein RS. Iliac crest bone graft harvest donor site morbidity. A statistical evaluation. Spine (Phila Pa 1976). 1995;20(9):1055-1060.

4. Sasso RC, LeHuec JC, Shaffrey C. Iliac crest bone graft donor site pain after anterior lumbar interbody fusion: a prospective patient satisfaction outcome assessment. J Spinal Disord Tech. 2005;18(suppl):S77-S81.

5. Ahlmann E, Patzakis M, Roidis N, et al. Comparison of ante- 
rior and posterior iliac crest bone grafts in terms of harvestsite morbidity and functional outcomes. J Bone Joint Surg Am. 2002;84(5):716-720.

6. Cahill KS, Chi JH, Day A, Claus EB. Prevalence, complications, and hospital charges associated with use of bonemorphogenetic proteins in spinal fusion procedures. JAMA. 2009;302(1):58-66.

7. Dagostino PR, Whitmore RG, Smith GA, et al. Impact of bone morphogenetic proteins on frequency of revision surgery, use of autograft bone, and total hospital charges in surgery for lumbar degenerative disease: review of the Nationwide Inpatient Sample from 2002 to 2008. Spine J. 2014; 14(1):20-30.

8. Burkus JK, Gornet MF, Schuler TC, et al. Six-year outcomes of anterior lumbar interbody arthrodesis with use of interbody fusion cages and recombinant human bone morphogenetic protein-2. J Bone Joint Surg Am. 2009;91(5):1181-1189.

9. Burkus JK, Sandhu HS, Gornet MF, Longley MC. Use of rhBMP-2 in combination with structural cortical allografts: clinical and radiographic outcomes in anterior lumbar spinal surgery. J Bone Joint Surg Am. 2005;87(6):1205-1212.

10. Food and Drug Administration. FDA Public Health Notification: Life-Threatening Complications Associated with Recombinant Human Bone Morphogenetic Protein in Cervical Spine Fusion. July 1, 2008. Accessed April 11, 2021. https:// wayback.archive-it.org/7993/20170111190511/http://www.fda. gov/MedicalDevices/Safety/AlertsandNotices/PublicHealth Notifications/ucm062000.htm

11. Singh K, Nandyala SV, Marquez-Lara A, Fineberg SJ. Epidemiological trends in the utilization of bone morphogenetic protein in spinal fusions from 2002 to 2011. Spine (Phila Pa 1976). 2014;39(6):491-496.

12. De La Garza Ramos R, Nakhla J, Bhashyam N, et al. Trends in the use of bone morphogenetic protein-2 in adult spinal deformity surgery: a 10 -year analysis of 54054 patients. Int $J$ Spine Surg. 2018;12(4):453-459.

13. Guzman JZ, Merrill RK, Kim JS, et al. Bone morphogenetic protein use in spine surgery in the United States: how have we responded to the warnings? Spine J. 2017;17(9):12471254.

14. Carragee EJ, Hurwitz EL, Weiner BK. A critical review of recombinant human bone morphogenetic protein-2 trials in spinal surgery: emerging safety concerns and lessons learned. Spine J. 2011;11(6):471-491.

15. Ong KL, Villarraga ML, Lau E, et al. Off-label use of bone morphogenetic proteins in the United States using administrative data. Spine (Phila Pa 1976). 2010;35(19):1794-1800.

16. Virk S, Sandhu HS, Khan SN. Cost effectiveness analysis of graft options in spinal fusion surgery using a Markov model. J Spinal Disord Tech. 2012;25(7):E204-E210.

17. Alvin MD, Derakhshan A, Lubelski D, et al. Cost-utility analysis of 1- and 2-level dorsal lumbar fusions with and without recombinant human bone morphogenic protein-2 at 1-year follow-up. Clin Spine Surg. 2016;29(1):E28-E33.

18. Medtronic. Infuse Bone Graft. Accessed April 11, 2021. https://www.medtronic.com/us-en/healthcare-professionals/ products/spinal-orthopaedic/bone-grafting/infuse-bone-graft. html

19. Luo X, Pietrobon R, Sun SX, et al. Estimates and patterns of direct health care expenditures among individuals with back pain in the United States. Spine (Phila Pa 1976). 2004;29(1): 79-86.

20. Martin BI, Mirza SK, Spina N, et al. Trends in lumbar fusion procedure rates and associated hospital costs for degenerative spinal diseases in the United States, 2004 to 2015. Spine (Phila Pa 1976). 2019;44(5):369-376.

21. Weinstein JN, Lurie JD, Olson PR, et al. United States' trends and regional variations in lumbar spine surgery: 1992-2003. Spine (Phila Pa 1976). 2006;31(23):2707-2714.
22. Hofstetter CP, Hofer AS, Levi AD. Exploratory meta-analysis on dose-related efficacy and morbidity of bone morphogenetic protein in spinal arthrodesis surgery. J Neurosurg Spine. 2016;24(3):457-475.

23. Zhao B, Tyree GA, Lin TC, et al. Effects of a surgical receipt program on the supply costs of five general surgery procedures. J Surg Res. 2019;236:110-118.

24. Jackson CR, Eavey RD, Francis DO. Surgeon awareness of operating room supply costs. Ann Otol Rhinol Laryngol. 2016;125(5):369-377.

25. Pahlavan S, Berven S, Bederman SS. Variation in costs of spinal implants in United States academic medical centers. Spine (Phila Pa 1976). 2016;41(6):515-521.

26. Zygourakis CC, Valencia V, Moriates C, et al. Association between surgeon scorecard use and operating room costs. JAMA Surg. 2017;152(3):284-291.

27. Childers CP, Showen A, Nuckols T, Maggard-Gibbons M. Interventions to reduce intraoperative costs: a systematic review. Ann Surg. 2018;268(1):48-57.

28. Pasquali JL, Knapp AM, Farradji A, Weryha A. Mapping of four light chain-associated idiotopes of a human monoclonal rheumatoid factor. J Immunol. 1987;139(3):818-823.

29. Macario A, Dexter F, Traub RD. Hospital profitability per hour of operating room time can vary among surgeons. Anesth Analg. 2001;93(3):669-675.

30. Adkison MA, Stott JL, Osburn BI. Identification of bluetongue virus protein-specific antibody responses in sheep by immunoblotting. Am J Vet Res. 1987;48(8):1194-1198.

31. Epstein NE. Complications due to the use of BMP/INFUSE in spine surgery: the evidence continues to mount. Surg Neurol Int. 2013;4(5)(suppl 5):S343-S352.

32. Carragee EJ, Mitsunaga KA, Hurwitz EL, Scuderi GJ. Retrograde ejaculation after anterior lumbar interbody fusion using rhBMP-2: a cohort controlled study. Spine J. 2011;11(6): 511-516.

33. Chrastil J, Patel AA. Complications associated with posterior and transforaminal lumbar interbody fusion. J Am Acad Orthop Surg. 2012;20(5):283-291.

34. Comer GC, Smith MW, Hurwitz EL, et al. Retrograde ejaculation after anterior lumbar interbody fusion with and without bone morphogenetic protein-2 augmentation: a 10-year cohort controlled study. Spine J. 2012;12(10):881-890.

35. Deutsch H. High-dose bone morphogenetic protein-induced ectopic abdomen bone growth. Spine J. 2010;10(2):e1-e4.

36. Devine JG, Dettori JR, France JC, et al. The use of rhBMP in spine surgery: is there a cancer risk? Evid Based Spine Care J. 2012;3(2):35-41.

37. Even J, Eskander M, Kang J. Bone morphogenetic protein in spine surgery: current and future uses. J Am Acad Orthop Surg. 2012;20(9):547-552.

38. Moatz B, Tortolani PJ. Transforaminal lumbar interbody fusion and posterior lumbar interbody fusion utilizing BMP-2 in treatment of degenerative spondylolisthesis: neither safe nor cost effective. Surg Neurol Int. 2013;4(2)(suppl 2):S67S73.

39. Woo EJ. Recombinant human bone morphogenetic protein-2: adverse events reported to the Manufacturer and User Facility Device Experience database. Spine J. 2012;12(10): 894-899.

40. Medical Advisory Secretariat. Bone morphogenetic proteins \& spinal surgery for degenarative disc disease: an evidencebased analysis. Ont Health Technol Assess Ser. 2004;4(4): $1-16$.

41. Epstein NE. Pros, cons, and costs of INFUSE in spinal surgery. Surg Neurol Int. 2011;2:10.

\section{Disclosures}

The authors report no conflict of interest concerning the materi- 
als or methods used in this study or the findings specified in this paper.

\section{Author Contributions}

Conception and design: Saigal. Acquisition of data: McGrath, Robinson. Analysis and interpretation of data: Saigal, McGrath, Robinson. Drafting the article: Saigal, McGrath. Critically revising the article: Saigal, McGrath, Feroze, Nistal. Reviewed submitted version of manuscript: all authors. Approved the final version of the manuscript on behalf of all authors: Saigal. Statistical analysis: McGrath, Nistal, Robinson. Study supervision: Saigal.

\section{Supplemental Information}

Previous Presentations

Some of these data were presented at Spine Summit 2019: AANS/ CNS Section on Disorders of the Spine and Peripheral Nerves, Miami, Florida, March 14-17, 2019.

\section{Correspondence}

Rajiv Saigal: University of Washington, Harborview Medical Center, Seattle, WA. respub2@uw.edu. 